\title{
Pharmacotherapy of Immunopathological Syndromes Among Patients with Systemic Lupus Erythematosus Based on ABC/VEN Analysis
}

\section{Ihor Hayduchok*}

Lviv Medical Institute, Lviv, Ukraine

*Corresponding Author: Ihor Hayduchok, Lviv Medical Institute, Lviv, Ukraine.
Received: April 07, 2021

Published: May 15, 2021

(C) All rights are reserved by Ihor Hayduchok.

\begin{abstract}
The article presents the results of the research of pharmacotherapy of immunopathological syndromes among patients with systemic lupus erythematosus based on ABC/VEN analysis. Systemic lupus erythematosus is a systemic autoimmune disease that develops as a result of combined disorders of the immune system that lead to a chronic inflammatory process in many tissues and organs. Comprehensive understanding of immunopathological syndromes among patients with SLE is important for correct diagnosis and proper pharmacotherapy. With the spread of the coronavirus pandemic, the role of pharmacotherapy of immunopathological syndromes among patients with dual health disorders and in patients with systemic diseases becomes very relevant. Pharmacotherapy of immunopathological syndromes among patients with SLE is carried out against the background of basic therapy in accordance with the clinical protocol of medical care on the basis of international and national regulations. Using the ABC/VEN analysis author formed a list of drugs used in pharmacotherapy keeping in mind average cost of treatment.
\end{abstract}

Keywords: Systemic Lupus Erythematosus; Immunopathological Syndromes; Pharmacotherapy; ABC/VEN Analysis

\section{Introduction}

Systemic lupus erythematosus (SLE) is a systemic autoimmune disease that develops as a result of combined disorders of the immune system that lead to a chronic inflammatory process in many tissues and organs [1].

SLE has the code of the International Classification of Diseases 10 edition M32 and the code of the International Classification for Primary Care-2 is L99.

Chronic inflammatory process causes the development of immunopathological syndromes and comorbidities (gastrointestinal, circulatory and hepatic disorders, cardiovascular, oncological, psychoneurological, endocrinological, addictive, respiratory system (diffuse alveolar bleeding, pain of various origins, etc.) [2,3].

According to the scientific literature, in the epidemiology of the disease, women suffer from systemic lupus erythematosus 6 - 10 times more often than men. SLE is recorded in the age group of 16 - 55 years in $75 \%$ of cases [4].
An analysis of the incidence and prevalence of SLE worldwide and their variations by age, gender, ethnicity and time were obtained in North America. The lowest incidence of SLE was reported in Africa and Ukraine (0.3 per 100,000 person-years), and the lowest prevalence was in Northern Australia ( 0 cases in a sample of 847). The incidence peaked in middle adulthood, and later among men. People of black ethnicity had the highest incidence and prevalence of SLE, while people of white ethnicity had the lowest incidence and prevalence. The prevalence of SLE was higher in males than in US females [5].

Patients with SLE in Spain have a later mean age at onset than the African American population in Spain [6].

Monitoring the incidence of SLE indicates that its prevalence has been increasing in the UK in recent years. The risk factors for SLE are age, gender, region of residence of the patient, ethnicity [7].

The average age of onset of the disease was 54 years in Switzerland [8]. 
The median time to diagnosis of SLE was 2.05 years in Denmark [9].

Comprehensive understanding of immunopathological syndromes among patients with SLE is important for correct diagnosis and proper pharmacotherapy $[10,11]$.

With the spread of the coronavirus pandemic, the role of pharmacotherapy of immunopathological syndromes in patients with dual health disorders and among patients with systemic diseases (control regime of antibacterial drugs for pharmacotherapy of coronavirus disease (COVID-19) among patients with dual disorders: newsletter) becomes very relevant [12-14].

Today it is important to use modern, effective and safe drugs for pharmacotherapy of immunopathological syndromes in patients with systemic autoimmune diseases, in particular systemic lupus erythematosus (ICD-10 code M32). ABC/VEN analysis is used to select effective and safe drugs.

\section{Aim of the Study}

The aim is to research pharmacotherapy of immunopathological syndromes among patients with systemic lupus erythematosus based on ABC/VEN analysis.

\section{Materials and Methods of the Research}

According to the clinical and pharmacological group for pharmacotherapy of immunopathological syndromes among patients with systemic lupus erythematosus were selected drugs that have the diagnostic code ATC - Classification (ATC) A05BA03 "Drugs used in liver disease, lipotropic substances" [15].

To assess the cost of pharmacotherapy for immunopathological syndromes, $\mathrm{ABC}$ analysis was performed as a tool to study the cost of purchasing drugs. ABC analysis involves the distribution of drugs from the most to the least expensive depending on their share among the indicators of the general purpose of drugs.

To assess the effectiveness of drug use, a VEN analysis was performed to classify drugs into categories $\mathrm{V}, \mathrm{E}$ and $\mathrm{N}$, taking into account regulatory documents (medical care standards, clinical protocols, State Form of Medicines, National List of Essential Medicines) and principles of evidence-based medicine (evidence of efficacy, quality, safety, economy, affordability) [16-18].
The research of the article is a fragment of research works of Lviv Medical Institute LLC on the topic "Improvement of the drug circulation system during pharmacotherapy on the basis of evidentiary and judicial pharmacy, organization, technology, biopharmacy and pharmaceutical law" (state registration number 0120U105348, terms 2021-2026), Kharkiv Medical Academy of Postgraduate Education on "Improving the organizational and legal procedure for providing patients with drugs from the standpoint of forensic pharmacy, organization and management of pharmacy" (state registration number 0116U003137, terms 2016-2020) and "Pharmaceutical and medical law: integrated approaches to the system of drug circulation from the standpoint of forensic pharmacy and organization of pharmaceutical business" (state registration number D/21 U000031, terms 2021-2026).

\section{Results and Discussion}

The approximate duration of pharmacotherapy for immunopathological syndromes among patients with SLE in hospital (specialized rheumatology departments) is 14 - 20 days, provided the selection of an adequate effective pharmacotherapeutic program, improvement of clinical and laboratory signs of the disease. Due to the polymorphic nature of the disease, pharmacotherapy is always selected individually. During pharmacotherapy of immunopathological syndromes among patients with SLE, the elimination of pathological syndromes, control of the active phase of the disease, prevention of exacerbations, minimization of side effects of drugs, as well as improving quality of life and prognosis [19,20].

Pharmacotherapy of immunopathological syndromes among patients with SLE is carried out against the background of basic therapy in accordance with the clinical protocol of medical care on the basis of international and national regulations. The lists of drugs were 13 INN (Hydroxychloroquine, Acetylsalicylic acid, Heparin, Rituximab, Methotrexate, Betamethasone, Dexamethasone, Azathioprine, Cyclophosphamide, Meloxicam, Alprostadil, Mycophenolic acid, Belimumab).

Clinical, biochemical and morphological analyzes among 145 patients showed that the use of Hepabene (according to INN Silymarin ATC code A05BA03) for the pharmacotherapy of patients with hepatobiliary disorders showed clinical and biochemical remission in a short time, which allowed to recommend Hepabene as a highly effective drug [21-23]. 
The range of drugs for pharmacotherapy of immunopathological syndromes in patients with systemic lupus erythematosus includes 11 drugs according to INN Silymarin: A05BA03 - Drugs used in liver disease, lipotropic substances. By trade names - 11 drugs: Silymarin Sandoz; Legalon; Silibor forte; Silibor max; Silibor 35; Heparsil; Carsil forte; Darsil; Hepabene; Carsil [24,25].

Found that for the pharmacotherapy of immunopathological syndromes among patients with systemic lupus erythematosus the most saturated is the share of drugs of classification subgroup A05B "Drugs used in liver disease, lipotropic substances", which has 11 trade names of drugs and is $50 \%$ of the total range.

The structure of the range of drugs according to INN Silymarin code A05BA03 for pharmacotherapy of immunopathological syndromes in patients with systemic lupus erythematosus includes the following trade names: Silymarin Sandoz; Legalon; Silibor forte; Silibor max; Silibor 35; Heparsil; Carsil forte; Darsil; Hepabene; Carsil.

The next stage of the study was the implementation of marketing rating analysis to determine the countries-manufacturers of drugs used in pharmacotherapy of immunopathological syndromes in patients with systemic lupus erythematosus (Table 1).

\begin{tabular}{|c|c|c|}
\hline No. & Trade name & Country-manufacturer \\
\hline 1 & 2 & 3 \\
\hline & Silymarin Sandoz & Germany \\
\hline & Legalon & Germany \\
\hline & Silibor forte & Ukraine \\
\hline & Silibor max & Ukraine \\
\hline & Silibor 35 & Ukraine \\
\hline & Heparsil & Ukraine \\
\hline & Carsil forte & Bulgaria \\
\hline & Darsil & Ukraine \\
\hline & Hepabene & Germany \\
\hline & Carsil & Bulgaria \\
\hline
\end{tabular}

Table 1: List of countries-manufacturers of drugs according to INN Silymarin code A05BA03 for pharmacotherapy of immunopathological syndromes among patients with systemic lupus erythematosus on the pharmaceutical market of Ukraine.
According to the results of marketing analysis of Silymarin-producing countries under code A05BA03 (Table 2) established that 5 drugs (Silymarin Sandoz, Legalon, Carsil forte, Hepabene, Carsil) supplied to the pharmaceutical market of Ukraine from abroad and 5 drugs manufactured by domestic manufacturers (Silibor forte, Silibor max, Silibor 35, Heparsil, Darsil).

Thus, drugs of foreign manufacturers supplied to Ukraine from 2 countries (Germany, Bulgaria), their number in this market segment is $30 \%$ (in particular, Hepabene) and 20\%, respectively. Ukraine also occupies $50 \%$ of the pharmaceutical market segment of drug manufacturers used for pharmacotherapy of immunopathological syndromes in patients with systemic lupus erythematosus.

\begin{tabular}{|c|c|c|}
\hline No. & $\begin{array}{l}\text { Trade } \\
\text { name }\end{array}$ & $\begin{array}{l}\text { Number, validity period from/until } \\
\text { according to the registration certificate } \\
\text { of the medicines }\end{array}$ \\
\hline \multirow[t]{11}{*}{1} & 2 & 3 \\
\hline & Triosil & $\begin{array}{l}\mathrm{UA} / 17202 / 01 / 01 \\
\begin{array}{l}11.01 .2019 \\
11.01 .2024\end{array}\end{array}$ \\
\hline & Legalon & $\begin{array}{c}\mathrm{UA} / 7185 / 01 / 01 \\
\text { unlimited from 20.02.2018 }\end{array}$ \\
\hline & $\begin{array}{l}\text { Silibor } \\
\text { forte }\end{array}$ & $\begin{array}{c}\mathrm{UA} / 5114 / 02 / 02 \\
\text { unlimited from } 08.12 .2017\end{array}$ \\
\hline & $\begin{array}{l}\text { Silibor } \\
\max \end{array}$ & $\begin{array}{c}\mathrm{UA} / 5114 / 02 / 01 \\
\text { unlimited from } 17.11 .2017\end{array}$ \\
\hline & Silibor 35 & $\begin{array}{c}\mathrm{UA} / 5114 / 01 / 01 \\
\text { unlimited from } 10.12 .2020\end{array}$ \\
\hline & Fumart & $\begin{array}{c}\mathrm{UA} / 17593 / 01 / 0116.08 .2019 \\
16.08 .2024\end{array}$ \\
\hline & Carsil forte & $\begin{array}{c}\mathrm{UA} / 2773 / 01 / 02 \\
\text { unlimited from } 08.10 .2018\end{array}$ \\
\hline & Darsil & $\begin{array}{c}\mathrm{UA} / 2473 / 01 / 01 \\
\text { unlimited from 30.08.2019 }\end{array}$ \\
\hline & Carsil & $\begin{array}{c}\mathrm{UA} / 2773 / 01 / 01 \\
\text { unlimited from } 08.05 .2019\end{array}$ \\
\hline & Hepabene & $\begin{array}{c}\mathrm{UA} / 2381 / 01 / 01 \\
\text { unlimited from } 04.04 .2019\end{array}$ \\
\hline
\end{tabular}

Table 2: List of drugs registered in Ukraine by INN Silymarin under code A05BA03 for pharmacotherapy of immunopathological syndromes among patients with systemic lupus erythematosus. 
The main countries-exporters of INN Silymarin drugs under code A05BA03 for pharmacotherapy of immunopathological syndromes in patients with systemic lupus erythematosus are Germany (30\%) and Bulgaria (20\%).

The next stage of the research was to study the range of drugs according to INN Silymarin code A05BA03 for pharmacotherapy of immunopathological syndromes in patients with systemic lupus erythematosus according to the dosage forms in table 3.

\begin{tabular}{|c|c|c|}
\hline No. & Trade name & Dosage form \\
\hline 1 & 2 & 3 \\
\hline & \multirow[t]{3}{*}{ Triosil } & Tablets of $22,5 \mathrm{mg}$ N.30 \\
\hline & & Tablets of $22,5 \mathrm{mg}$ N.50 \\
\hline & & Tablets of 22,5 mg N.100 \\
\hline & \multirow[t]{6}{*}{ Legalon } & Capsules of 140 mg N. 20 \\
\hline & & Capsules of 140 mg N. 30 \\
\hline & & Capsules of 140 мг N. 60 \\
\hline & & Capsules of 70 mg N. 20 \\
\hline & & Capsules of $70 \mathrm{mg} \mathrm{N} .30$ \\
\hline & & Capsules of 70 mg N. 60 \\
\hline & \multirow[t]{2}{*}{ Silibor forte } & Capsules of 70 mg N. 20 \\
\hline & & Capsules of 70 mg N. 40 \\
\hline & \multirow[t]{2}{*}{ Silibor max } & Capsules of 140 mg N. 20 \\
\hline & & Capsules of 140 mg N. 40 \\
\hline & \multirow[t]{4}{*}{ Silibor 35} & Coated tablets of $35 \mathrm{mg} \mathrm{N.} 20$ \\
\hline & & Coated tablets of 35 mg N. 25 \\
\hline & & Coated tablets of $35 \mathrm{mg} \mathrm{N.} 30$ \\
\hline & & Coated tablets of 35 mg N. 80 \\
\hline & \multirow[t]{2}{*}{ Fumart } & Capsules of 50 mg N. 20 \\
\hline & & Capsules of 50 mg N. 30 \\
\hline & Carsil forte & Hard capsules of $90 \mathrm{mg} \mathrm{N} .30$ \\
\hline & \multirow[t]{3}{*}{ Darsil } & Coated tablets of $22,5 \mathrm{mg} \mathrm{N}$. 30 \\
\hline & & Coated tablets of $22,5 \mathrm{mg} \mathrm{N} .50$ \\
\hline & & Coated tablets of $22,5 \mathrm{mg} \mathrm{N} .100$ \\
\hline & Carsil & Coated tablets of $22,5 \mathrm{mg} \mathrm{N} .80$ \\
\hline & Hepabene & Hard capsules N. 30 \\
\hline
\end{tabular}

Table 3: The range of drugs according to INN Silymarin code A05BA03 for pharmacotherapy of immunopathological syndromes among patients with systemic lupus erythematosus by dosage forms.
According to the results of the study of drugs by INN Silymarin code A05BA03 for pharmacotherapy of immunopathological syndromes among patients with systemic lupus erythematosus by dosage forms (Table 3 and figure 1), most of the studied drugs are presented on the pharmaceutical market of Ukraine in capsules $56,0 \%$ (particularly Hepabene).

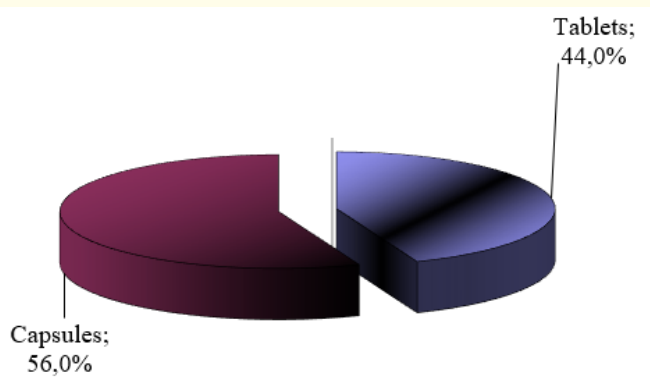

Figure 1: Distribution of drugs according to INN Silymarin code A05BA03 for pharmacotherapy of immunopathological syndromes among patients with systemic lupus erythematosus by types of dosage forms.

At the next stage of the study, the ratio of dosage forms to companies - manufacturers was calculated: Silymarin and in the form of $2 \mathrm{LF}$ produced by 7 pharmaceutical companies.

It should be noted that the studied drugs under INN Silymarin code A05BA03 for pharmacotherapy of immunopathological syndromes among patients with systemic lupus erythematosus are registered in Ukraine and have a validity of the registration certificate of the drug (Table 3 and figure 2): unlimited validity of the certificate have $80 \%$ (particularly Hepabene).

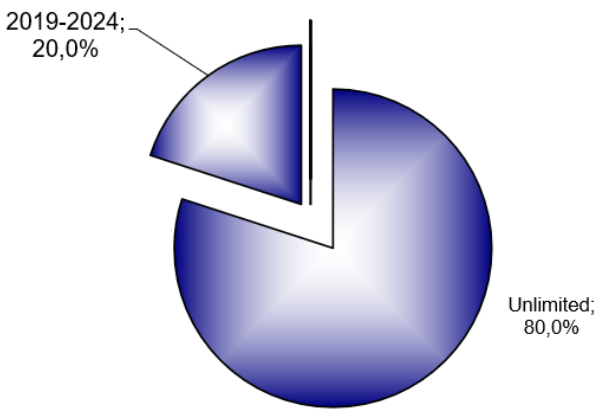

Figure 2: Validity of registration certificates of medicinal products according to INN Silymarin code A05BA03 for pharmacotherapy of immunopathological syndromes in patients with systemic lupus erythematosus. 
The next stage of research was the ABC/VEN-analysis, which involves the distribution of drugs by the cost of pharmacotherapy and evaluation of the effectiveness of drug use in a healthcare facility (Table 4).

\begin{tabular}{|c|c|c|c|c|c|c|}
\hline No. & $\begin{array}{c}\text { VEN } \\
\text { group }\end{array}$ & Trade name & $\begin{array}{c}\text { Cost } \\
\text { per unit } \\
\text { dose } \\
\text { (UAH) }\end{array}$ & $\begin{array}{c}\text { Specific } \\
\text { weight } \\
\text { (\%) }\end{array}$ & $\begin{array}{c}\text { Cumu- } \\
\text { lative } \\
\text { share } \\
\text { (\%) }\end{array}$ & $\begin{array}{c}\text { ABC } \\
\text { group }\end{array}$ \\
\hline E & Hepabene & 6,67 & 19,45 & 19,45 & A \\
\hline E & Carsil forte & 5,83 & 17,00 & 36,45 & A \\
\hline E & Silibor max & 5,35 & 15,60 & 52,05 & A \\
\hline E & Fumart & 4,38 & 12,77 & 64,82 & A \\
\hline E & Legalon & 3,05 & 8,89 & 73,71 & A \\
\hline E & Silibor forte & 2,91 & 8,48 & 82,19 & A \\
\hline \multicolumn{2}{|c|}{ Total for group A } & 28,19 & 82,19 & - & 6 \\
\hline & E & Carsil & 1,93 & 5,62 & 87,81 & B \\
\hline \multicolumn{2}{|c|}{ E } & Silibor 35 & 1,41 & 4,11 & 91,92 & B \\
\hline \multicolumn{2}{|c|}{ E } & Triosil & 1,40 & 4,08 & 96 & B \\
\hline \multicolumn{2}{|c|}{ Total for group B } & 4,74 & 13,81 & - & 3 \\
\hline \multicolumn{2}{|c|}{ Total for groups AB } & 32,93 & 94,6 & 94,6 & 17 \\
\hline \multicolumn{2}{|c|}{ E } & Darsil & 1,37 & 4,00 & 100,00 & C \\
\hline \multicolumn{2}{|c|}{ Total for group C } & 1,37 & 4,00 & - & 1 \\
\hline \multicolumn{2}{|c|}{ Total for groups ABC } & 34,3 & 100 & 100 & 10 \\
\hline
\end{tabular}

Table 4: ABC-VEN - analysis of drugs by INN Silymarin code A05BA03 for pharmacotherapy of immunopathological syndromes among patients with systemic lupus erythematosus.

According to the results of the $\mathrm{ABC}$ analysis, category A included drugs whose use was equal to $80.0 \%$ of the total rate of use; to group B - $15.0 \%$, and to group C - 5.0\%.
Category A includes 6 drugs (in particular, Hepabene), the cost of which per unit dose is UAH 28.19 , which is $82.19 \%$ of the total cost of treatment of the patient.

Category B includes 3 drugs (in particular, Carsil) whose total cost per unit dose is UAH 4.74 (13.81\%), and category C includes 1 drug (Darsil) with a cost of UAH 1.37 per unit dose (4.00\%).

According to the results of VEN analysis, it was established that the studied drugs belong to group E (100\%).

Group V (vital) N (secondary) and did not include any drug.

The distribution of drugs according to the results of VEN analysis is shown in figure 3.
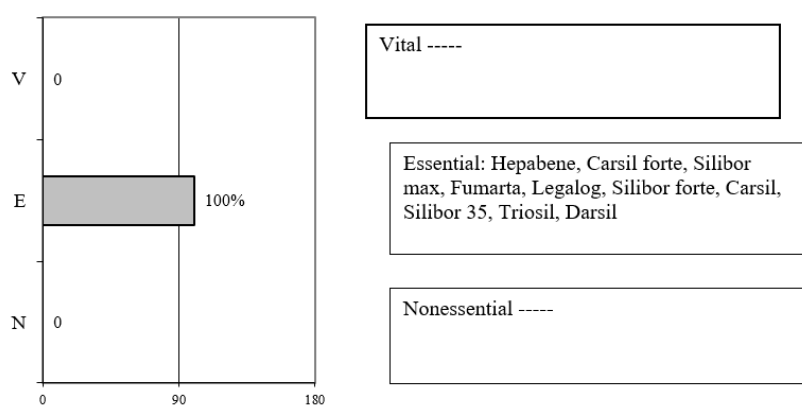

Figure 3: Distribution according to the results of VEN-analysis of investigational drugs according to INN Silymarin code A05BA03

for pharmacotherapy of immunopathological syndromes in patients with systemic lupus erythematosus.

Based on the ABC/VEN analysis, a matrix of the consolidated $\mathrm{ABC} / \mathrm{VEN}$ analysis was developed (Table 5).

\begin{tabular}{|c|c|c|c|c|c|c|c|c|c|}
\hline \multirow{3}{*}{$\begin{array}{l}\text { Drug } \\
\text { group }\end{array}$} & \multirow{3}{*}{$\begin{array}{l}\text { Quantity } \\
\text { of drugs }\end{array}$} & \multirow{2}{*}{\multicolumn{2}{|c|}{$\begin{array}{c}\text { V } \\
\text { Purpose of drug }\end{array}$}} & \multirow{3}{*}{$\begin{array}{l}\text { Quantity } \\
\text { of drugs }\end{array}$} & \multirow{2}{*}{\multicolumn{2}{|c|}{\begin{tabular}{|c|} 
E \\
Purpose of drug \\
\end{tabular}}} & \multirow{3}{*}{$\begin{array}{l}\text { Quantity } \\
\text { of drugs }\end{array}$} & \multirow{2}{*}{\multicolumn{2}{|c|}{$\begin{array}{c}\text { N } \\
\text { Purpose of drug }\end{array}$}} \\
\hline & & & & & & & & & \\
\hline & & UAH & $\%$ & & UAH & $\%$ & & UAH & $\%$ \\
\hline A & - & - & - & 6 & 28,19 & 82,19 & - & - & - \\
\hline$B$ & - & - & - & 3 & 4,74 & 13,81 & - & - & - \\
\hline C & - & - & - & 1 & 1,37 & 4,00 & - & - & - \\
\hline Разом: & - & - & - & 36 & 34,3 & 100 & - & - & - \\
\hline
\end{tabular}

Table 5: Matrix of consolidated ABC/VEN - analysis of investigational drugs according to INN Silymarin code A05BA03 for pharmacotherapy of immunopathological syndromes in patients with systemic lupus erythematosus. 
Conducted studies show that category E drugs (in particular, Hepabene) accounted for the highest costs of $100 \%$, group $\mathrm{N}$ and group V - no costs.

Share of costs accounted for by drugs:

- $\quad$ By category of A/E (82.19\%) was the largest indicator of the general purpose indicator (in particular, Hepabene).

- $\quad$ By categories of B/E - 13.81\%.

- $\quad$ By categories of $\mathrm{B} / \mathrm{V}$ and $\mathrm{B} / \mathrm{N}-0 \%$.

- Drugs for group $\mathrm{C}$ had the corresponding indicators: $\mathrm{C} / \mathrm{E}$ $4.00 \%$; $\mathrm{C} / \mathrm{N}-0.6 \%$; $\mathrm{C} / \mathrm{V}-0 \%$.

\section{Conclusion}

The relevance and necessity of the chosen research topic as a result of a review of the scientific literature on epidemiology and pharmacotherapy are substantiated.

Marketing research of INN Silymarin drugs under code A05BA03 for pharmacotherapy of immunopathological syndromes in patients with systemic lupus erythematosus by assortment, countries of origin, dosage forms, and registration certificates were carried out.

According to the results of the $\mathrm{ABC}$ analysis, the drugs were distributed according to the INN Silymarin code A05BA03 in descending order of value. Use of Hepabene (specific weight 19.45\%) for pharmacotherapy of immunopathological syndromes among patients with systemic lupus erythematosus.

According to the results of VEN analysis, proved that the investigational drugs under the INN Silymarin code A05BA03 belong to category E (in particular, Hepabene).

In terms of priority for pharmacotherapy of immunopathological syndromes in patients with systemic lupus erythematosus, a matrix of consolidated ABC/VEN analysis developed. Noted that the largest share of costs (82.19\%) fell on the category of A/E (in particular, Hepabene).

The results of the study provide an opportunity to make administrative and managerial decisions in determining the pharmacotherapy of immunopathological syndromes to improve the use of drugs among patients with systemic lupus erythematosus.

\section{Bibliography}

1. M Cojocaru., et al. "Manifestations of Systemic Lupus Erythematosus". Maedica (Bucur) 6.4 (2011): 330-336.

2. “Systemic Lupus Erythematosus (SLE)”. CDC (2021).

3. Zhi-Chao Yuan., et al. "Gene polymorphisms and serum levels of sVEGFR-1 in patients with systemic lupus erythematosus". Scientific Report 10.1 (2020): 15-31.

4. F Rees., et al. "The worldwide incidence and prevalence of systemic lupus erythematosus: a systematic review of epidemiological studies". Rheumatology (Oxford) 56.11 (2017): 19451961.

5. S Jarukitsopa., et al. "Epidemiology of systemic lupus erythematosus and cutaneous lupus erythematosus in a predominantly white population in the United States". Arthritis Care and Research (Hoboken) 67.6 (2015): 817-828.

6. M Alonso., et al. "Systemic lupus erythematosus in northwestern Spain: a 20-year epidemiologic study". Medicine (Baltimore) 90.5 (2011): 350-358.

7. F Rees., et al. "The incidence and prevalence of systemic lupus erythematosus in the UK, 1999-2012". Annals of the Rheumatic Diseases 75.1 (2016): 136-141.

8. Gronhagen C., et al. "Cutaneous lupus erythematosus and the association with systemic lupus erythematosus: a populationbased cohort of 1088 patients in Sweden". The British Journal of Dermatology 164.6 (2011): 1335-1341.

9. M Petersen., et al. "Epidemiology of cutaneous lupus erythematosus and the associated risk of systemic lupus erythematosus: a nationwide cohort study in Denmark". Lupus 27.9 (2018): 1424-1430.

10. Kumutnart Chanprapaph., et al. "Dermatologic Manifestations, Histologic Features and Disease Progression among Cutaneous Lupus Erythematosus Subtypes: A Prospective Observational Study in Asians". Dermatology and Therapy 11.1 (2021): 131-147.

11. Eui Hyun Oh., et al. "Ten-year retrospective clinicohistological study of cutaneous lupus erythematosus in Korea". Journal of Dermatology 45.4 (2018): 436-443. 
12. Hayduchok IG., et al. "Control regime of antibacterial drugs for pharmacotherapy of coronavirus disease (COVID-19) among patients with dual disorders: an information letter about innovations". Hayduchok I.G., Shapovalova V.O., Shapovalov V.V., Shapovalov V.V. Research and development: Lviv Medical Institute LLC, KhMAPE of the Ministry of Health of Ukraine, Ukrmedpatentinform of the Ministry of Health of Ukraine. K.: Ukrmedpatentinform of the Ministry of Health of Ukraine 230 (2020): 6 .

13. Hayduchok IG., et al. Control regime of drugs for pharmacotherapy of coronavirus disease (COVID-19) in patients with systemic diseases: an information letter about innovations". Hayduchok I.G., Shapovalova V.O., Shapovalov V.V., Shapovalov V.V. Research and development: Lviv Medical Institute LLC, KhMAPO of the Ministry of Health of Ukraine, Ukrmedpatentinform of the Ministry of Health of Ukraine. K. Ukrmedpatentinform of the Ministry of Health of Ukraine 25225-2020 (2020): 6.

14. VO Shapovalova., et al. "Coronavirus disease pandemia 2019: growth of epidemic dangers". Acta Scientific Pharmaceutical Sciences 4.7 (2020): 61-68.

15. ATC-classification. [Electronic resource]. Compendium online.

16. On approval of the clinical protocol for providing of medical care to patients with systemic lupus erythematosus [Electronic resource]: Order of the Ministry of Health of Ukraine dated (2006).

17. National list of basic medicines [Electronic resource]: Resolution of the Cabinet of Ministers of Ukraine of (2009).

18. On approval of the twelfth issue of the State formulary of medicines and ensuring its availability [Electronic resource]: Order of the Ministry of Health of Ukraine dated (2020).

19. Shapovalov VV., et al. "Experience of the USA concerning and organization of healthcare system for the pharmaceutical provision for privileged categories of citizens [Electronic resourse]". Annals of Mechnikov Institute 1 (2019): 81-87.

20. Shapovalov VV., et al. "Experience of Great Britain in organization of healthcare system for pharmaceutical provision with medicines for privileged categories of citizens". Health of Society 78.1 (2019): 36-40.
21. Guideline 00446. Systemic lupus erythematosus. [Electronic resource]: Author: Heikki Julkunen. Original text editor: Anna Kattainen. Date of last update: (2017).

22. On approval of the List of medicines permitted for use in Ukraine, which are released without prescriptions from pharmacies and their structural units [Electronic resource]: Order of the Ministry of Health of Ukraine dated (2019).

23. V Shapovalov., et al. "Organizational and legal analysis of the pharmaceutical provision for the most common diseases of society". International Journal of Pharmaceutical Sciences Review and Research 51.1 (2018): 118-124.

24. V Shapovalov., et al. "Concerning the importance of forensic and pharmaceutical researches to improve patients' accessibility to medicines". Pharmacia 65.2 (2017): 23-29.

25. V Shapovalov., et al. "Forensic and pharmaceutical study of the presence of a causal link between the degree of alcohol abuse and qualification level of the respondents". Pharmacia 66.3 (2017): 31-39.

\section{Volume 4 Issue 6 June 2021}

(c) All rights are reserved by Ihor Hayduchok. 